\title{
Humberto \\ Márquez Covarrubias
}

El modelo económico-político vigente en México basado en la concentración de poder y riqueza, una plutonomía que ha prohijado una camada de magnates y una mayoría poblacional subsumida en la pauperización, se ha decantado hacia su lado más perverso: el realismo salvaje que articula el binomio violencia-inseguridad como ejercicio de control político. Las violencias sistémicas destruyen la simbiosis entre sociedad y naturaleza, en tanto que las violencias emergentes desencadenan estrategias coercitivas y punitivas que destruyen el tejido social, criminalizan a los sectores excluidos, minimizan la ciudadanía y precarizan el mundo del trabajo. 


\section{PLUTONOMÍA Y PAUPERIZACIÓN}

U na de las contradicciones más aberrantes de la sociedad mexicana es la diferenciación social extrema. Frente a un puñado de 11 multimillonarios, que en 2011 amasa una fortuna cercana a 112,300 millones de dólares - alrededor de $10 \%$ del producto interno bruto (PIB) nacional- deambulan más de 52 millones de pobres que carecen de los recursos más elementales para vivir con dignidad. Según la Organización para la Cooperación y el Desarrollo Económicos (OCDE), el ingreso promedio de la décima parte de los hogares más acaudalados fue de 228 mil 900 pesos mensuales, es decir, 26 veces el ingreso de su contraparte, la décima parte de los hogares depauperados que en promedio recibieron 8 mil 700 pesos mensuales. ${ }^{1}$ En las últimas dos décadas y media, periodo en el que se ha implementado una suerte de guerra de los ricos en contra de los pobres, los ingresos reales de los hogares opulentos crecieron $1.7 \%$ y el de los más depauperados sólo $0.8 \%$.

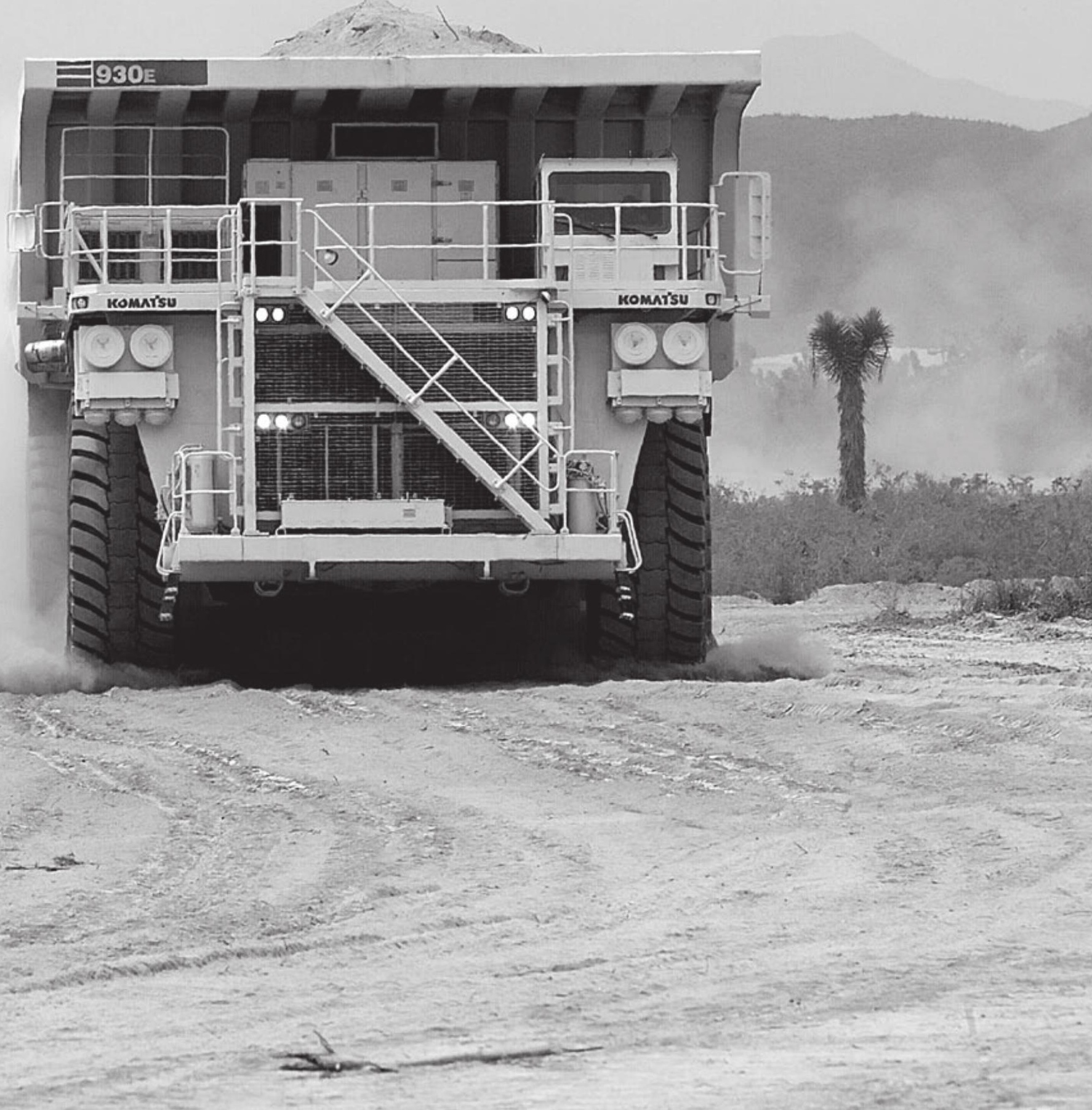


La plutonomía mexicana ha engendrado a magnates como Carlos Slim ligados a la tecnocracia, que puede perder 5 mil millones de dólares en un solo año y aún así preservar, por tercer año consecutivo, el reconocimiento mediático como el hombre más rico del orbe al detentar una fortuna valuada en 69 mil millones de dólares. ${ }^{2}$ La degradación humana aparece sólo como un frío signo estadístico que aqueja a millones de personas anónimas, el Consejo Nacional de Evaluación de la Política de Desarrollo Social (Coneval) estima que la pobreza está en aumento, al pasar de $42.7 \%$ a 51.3\% de la población. El México social está quebrantado, pues más de 20 millones de mexicanos están desempleados, 14 millones están inmersos en el comercio informal y 10 millones de jóvenes no tienen acceso a la escuela y el trabajo.

\section{RESPETABILÍSIMA CORRUPCIÓN Y SAQUEO}

Una economía basada en la concentración de capital y riqueza, además de fundarse en la acumulación por despojo, no puede estar ajena a la corrupción empresarial, el saqueo y el lavado de dinero. La corrupción suele justificarse como parte de la cultura popular y del arribismo de la clase política. Pero las prácticas corporativas están cimentadas en la corrupción. Una encuesta aplicada a cerca de 4 mil empresas nacionales y extranjeras revela que el 62\% de las corporaciones que operan en México soborna a funcionarios públicos para obtener privilegios o beneficios. ${ }^{3}$ Para ganar el dominio en el mercado mexicano, la corporación emblemática del expansionismo estadounidense, Walmart, pagó sobornos por 24 millones de dólares. Asimismo, es sabido que las grandes empresas evaden impuestos con el consentimiento hacendario y que el mismo gobierno organiza programas de rescate, como el llamado Fondo Bancario de Protección al Ahorro (Fobaproa), para canalizar recursos públicos a las arcas empresariales.

Entre 2001 y 2011, el sistema bancario instalado en México reportó utilidades por 682.8 mil millones de pesos, que representa un crecimiento real anual de $13.6 \%$. Entre $60 \%$ y $70 \%$ de las ganancias, provenientes principalmente del crédito al consumo, el cobro de altas comisiones y la especulación, se destinan a recapitalizar las casas matrices, en una suerte de neocolonialismo financista. ${ }^{4}$ Mientras que la banca española atraviesa por una profunda crisis financiera, desde México aumentan las remesas de ganancias: en 2011, Santander-México transfirió utilidades a la matriz ibérica por 936 millones de euros, equivalente a $67.5 \%$ de las ganancias de la filial — que de suyo representan un aumento de $40.9 \%$ respecto del año anteriory BBVA-Bancomer transfirió utilidades a la matriz por mil $741 \mathrm{mi}-$ llones de euros (49.2\% de las utilidades). ${ }^{5}$

El lavado de dinero aglutina redes empresariales con tentáculos transnacionales que involucran al crimen organizado y la banca comercial. Un ejemplo es la filial mexicana de HSBC que fue acusada de enviar 7 mil millones de dólares en efectivo a Estados Unidos en- tre 2007 y 2008 bajo la comisión de lavado de dinero. Se estima que los cárteles de la droga utilizan a los bancos mexicanos y estadounidenses para lavar dinero en montos aproximados a 39 mil millones de dólares cada año. ${ }^{6}$ En un supuesto acto de contrición, HSBC admitió que ha realizado este tipo de operaciones ilegales con recursos provenientes del narcotráfico, contrabando de armas y terrorismo en México, Irán, Siria y otros países. En México, sólo pagaron una multa de 379 millones de pesos. Otras corporaciones no bancarias, como Walmart, también están señaladas por incurrir en lavado de dinero.?

Con el supuesto arribo de la democracia electoral, en México se aposentaron a sus anchas los grandes grupos financieros, industriales y comerciales, que al derruir el sistema financiero nacional, llegaron a sugerir la instalación de una «democracia financiera» impelida por el «sano afán de lucro». En estricto sentido, no puede hablarse de que en el país se ha instaurado la democracia, cuando su principal componente, la democracia social, es prácticamente inexistente dado que la calidad de vida de la mayoría de las clases sociales está vulnerada. Pero la plutocracia, el gobierno de los ricos, que mandan obedeciendo a los consejos de administración y a los grandes accionistas, goza de salud inmejorable.

\section{REPRESIÓN SALARIAL Y DESPIDO LIBRE}

La guerra contra los trabajadores pretende acentuar la transferencia de valor del trabajo al capital. El salario mínimo que, en teoría, debería cubrir las necesidades básicas de los trabajadores y sus dependientes económicos, no es tal. Entre 2006 y 2012, el poder adquisitivo del salario mínimo cayó 43.1\%, para registrar una pérdida acumulada, en 25 años, del $79.11 \%{ }^{8}$ No obstante a la aparente estabilidad macroeconómica y la existencia de tasas de intereses relativamente bajas, la 
riqueza no se distribuye vía empleos dignos y prestaciones sociales: 6.7 millones de mexicanos perciben un minisalario, más de 3 millones no reciben compensación y 10 millones padecen excesiva precariedad.

Un dato sintomático de los estertores neoliberales es que la exportación manufacturera mexicana hacia Estados Unidos ha retomado bríos en rubros como carros de ferrocarril, cerveza, motores de vehículos, refrigeradores, televisores, tractores y motores eléctricos. La fórmula secreta de la reactivación competitiva no es un empuje tecnológico ni una premeditada política industrial, sino, una vez más, la represión salarial en un paradójico entorno internacional favorable. En la última década, el salario manufacturero promedio en China aumentó cuatro veces y en México se estancó: el diferencial salarial era de $237.9 \%$ y ahora es de sólo $7.3 \%{ }^{9}$ No obstante, las exportaciones mexicanas son realizadas, mayormente, por corporaciones estadounidenses, por lo que el dinamismo exportador es, en realidad, comercio intrafirma. Más aún, la estrategia de acumulación entre ambos países es notoriamente diferente, pues mientras que China experimenta un crecimiento superior a $8 \%$ respaldado por la recuperación salarial, la innovación tecnológica y la consolidación del mercado interno, México soporta el crecimiento exportador casi exclusivamente con estrategias que vulneran el fondo de vida obrero compuesto por el salario directo y el salario indirecto, en la manufacturera y, sobre todo, los servicios. La «competitividad» de la economía mexicana basada en el trabajo barato es insustentable, tanto porque siempre está latente la emergencia de algún lugar donde los salarios sean aún menores como porque es insostenible esta escalada de degradación humana y ambiental.

La élite económico-política insiste en profundizar el modelo del realismo salvaje. La coalición parlamentaria de derechas, capitaneada por el Partido Revolucionario Institucional (PRI) y el Partido Acción Nacional (PAN), implementa una nueva ofensi- va contra el mundo laboral, bajo la modalidad de un albazo legislativo, presentado como una perversa herencia política del «presidente del empleo» que se vale de la novísima figura legislativa de iniciativa preferente. La aprobación de la contrarreforma laboral, refrendada por el Consejo Coordinador Empresarial (CCE), pretende instaurar un régimen de despido libre, el pago por horas y la subcontratación, entre otras disposiciones que pretenden consolidar, de una vez, la inseguridad laboral.

\section{DEPENDENCIA ALIMENTARIA Y HAMBRUNA}

La paradoja del hambre en el mundo aflora cuando se atestigua que cada año mueren alrededor de 35 millones personas, no obstante que, según la Organización de las Naciones Unidas para la Agricultura y la Alimentación (FAO), existen alimentos suficientes para satisfacer las necesidades de 12 mil millones de personas, es decir, el doble de población mundial. Empero, el sistema agroalimentario mundial, que privilegia el despojo de tierras, la especulación y el predominio de agroindustrias como Monsanto y cadenas comerciales como Walmart, no tiene, en efecto, ninguna vocación humanista, pero sí denodados intereses corporativos.

En México, la cifra no es menos escandalosa: entre 2001 y 2012, la desnutrición arrojó 85 mil 343 mexicanos muertos, ${ }^{10}$ un monto superior, incluso, a las muertes ocasionadas por la violencia asociada a la guerra contra el narcotráfico en el mismo periodo: $80 \mathrm{mil}$ muertos. Según Coneval, en 2012 la «pobreza alimentaria» pasó de 14.7 millones a 21.2 millones en este sexenio, se trata de personas «sin capacidad para comprar la canasta básica con todo su ingreso», es decir, no disponen de ingresos suficientes para comprar frijol, tortilla, chile, leche, huevo y demás artículos. Para esos conjuntos familiares depauperados, el signo de la muerte aflora por desnutrición, pero también por un cúmulo de enfermedades asociadas a la hambruna y la proliferación de múltiples expresiones de inseguridad humana. Los fondos gubernamentales de «combate a la pobreza», encabezados por el Programa Oportunidades, no acometen las causas de fondo; la focalización de recursos paliativos sólo pretenden darle un rostro humano a la crisis humanitaria y preservar una base electoral para los gobiernos que, paradójicamente, aplican recetas que atentan contra el modo de vida y el trabajo de la mayoría de la población trabajadora y sus dependientes económicos.

Los problemas alimentarios se exacerbaron en el país con las contrarreformas constitucionales, el desmantelamiento de la institucionalidad rural, la reducción de subsidios al campo, la caída de la producción, el fomento de las importaciones a precios dumping y la concesión de privilegios a las grandes agroindustrias. Como resultado, la dependencia alimentaria en México se ha profundizado. El sector agropecuario aporta sólo el 4.1\% del pIB y la importación de 
alimentos asciende, en el gobierno actual, a 60 mil 165 millones de dólares, equivalentes al 30\% del valor total de la producción nacional generada en el mismo periodo. Entre 2001 y 2012 se erogaron 96 mil 500 millones de dólares para la compra de alimentos en los que México es cada vez menos autosuficiente e incrementa la vulnerabilidad ante las recurrentes embestidas especulativas en el sector agroalimentario. Durante el último sexenio, el déficit de la balanza comercial agropecuaria, un asunto de seguridad nacional, se profundizó 160\%: entre 2007 y julio de 2012, las importaciones rebasaron por un monto de 10 mil 958.3 millones de dólares a las exportaciones. ${ }^{11}$

La bancarrota inducida en el sector social del campo mexicano ha derivado en el resquebrajamiento de la reproducción demográfica: el despoblamiento inexorable que afecta a 915 municipios del país (65.2\% de los municipios rurales y $37.2 \%$ del total nacional). En 171 municipios dicha pérdida poblacional es severa y pudiera ser irreversible. ${ }^{12}$

\section{ECOCIDIO Y NUEVA FIEBRE DEL ORO}

La degradación ambiental está asociada a la fractura del metabolismo entre sociedad y naturaleza. El gran capital ha ensanchado sus fuentes de generación de riqueza a costa del desmantelamiento de la infraestructura natural, la destrucción de ecosistemas y la privatización de bienes comunitarios. Durante la vigencia del neoliberalismo, México se ha consolidado como el quinto mayor deforestador en el mundo: cada año sucumben entre 350 y 650 mil hectáreas de bosques y selvas. ${ }^{13}$ Distintos grados de contaminación afectan a 96\% de los cuerpos de agua superficial, es decir, el agua que circula o reposa sobre la superficie terrestre en forma de ríos, lagos, lagunas, pantanos, presas y otras formas. La mayor incidencia de contaminación ambiental acontece en zonas urbanas y periurbanas, principalmente en ciudades medias (entre 100 mil y un millón de habitantes) que carecen de planeación urbana y de control y prevención en materia de contaminación (aire, por fuentes móviles), agua (fuentes fijas) y suelos (ambas fuentes). ${ }^{14}$

México es el segundo país del mundo en tipos de ecosistemas y el cuarto en riqueza de especies. Los problemas ecológicos suelen considerarse como derivados del cambio climático, la pérdida de biodiversidad y ambientes naturales, la extinción de especies, la erosión y la contaminación. Los focos de alarma se prenden cuando se toma nota de que en los últimos 30 años se han perdido 50 especies animales y que $40 \%$ se encuentran en peligro de extinción. Además, la deforestación de manglares, selvas y bosques representa una pérdida anual de 600 mil hectáreas.

Los proyectos de «desarrollo» de corte extractivista degradan la naturaleza y propician crisis humanitarias. Los proyectos turísticos, como la Reserva de la Biosfera Chamela-Cuixmala, están vinculados al despojo de bienes comunes. Los proyectos de magaminería a cielo abierto, que pulverizan cerros enteros para sustraer partículas dispersas de oro o tierras «raras», destruyen el hábitat, desmantelan el sistema de subsistencia social y contaminan la infraestructura natural. Las grandes corporaciones se apropian de bienes comunes y bienes de la nación para sustraer recursos naturales y generar nichos de ganancia, como refugio capitalista ante el estallido de burbujas especulativas en otras latitudes y sectores productivos. $^{15}$

\section{¿LEGITIMIDAD BASADA EN LA MILITARIZACIÓN?}

La estrategia de seguridad de Estados Unidos pretende, entre otros objetivos, configurar un perímetro de protección sobre su territorio nacional y contener la oleada de gobiernos progresistas latinoamericanos. México representa la barrera de contención, el «patio trasero». Con el antecedente del Plan Colombia, el manto de la Iniciativa Mérida y la operación encubierta de agencias estadounidenses como Drug Enforcement Administration (DEA) y Federal Bureau of Investigation (FBI), en México se impone una llamada guerra contra el narcotráfico. En el plano interno, el gobierno derechista no pretende, sin embargo, atacar el nervio financiero y patrimonial ni desmantelar los vínculos transnacionales del crimen organizado, que no sólo involucra a los cárteles de la droga sino que también incluye al sistema financiero, empresas de diversos ramas y diversos personajes de la clase política, gobiernos y fuerza policial y militar. La estrategia principal consiste en militarizar la vida pública para legitimar al gobierno derechista que asumió el poder mediante el fraude electoral; preservar el modelo depredador y excluyente bajo un régimen de mano dura; preservar el control político de la población mediante estrategias coercitivas y punitivas; criminalizar a los pobres, principalmente los jóvenes; disuadir la 

ga, la delincuencia organizada y común y a millones de civiles que se arman para afrontar los peligros de la inseguridad. Organizaciones internacionales estiman que unos 20 millones de armas ilegales circulan en el país, cuando la Secretaría de la Defensa Nacional (Sedena) sólo ha autorizada a 5 millones 500 mil. ${ }^{17} \mathrm{El}$ saldo fúnebre es estrujante: 80 mil muertos, 30 mil desaparecidos, 250 mil desplazados de manera forzada, 20 mil huérfanos y 5 mil niños asesinados. ${ }^{18}$

El colofón tétrico involucra a sectores vulnerables sobreexpuestos a las diversas manifestaciones de las violencias, como las mujeres y los jóvenes pobres. Día con día, entre cuatro y cinco mujeres son asesinadas en el país. Entre 2007 y 2009 se cometieron 4 mil 379 feminicidios. ${ }^{19}$ Los jóvenes, y en muchos casos los infantes, están siendo reclutados por las bandas delincuenciales para realizar actividades que los coloca como carne de cañón, pero que al mismo tiempo los está formando en la industria criminal. Sectores sensibles para la vida democrática, como el periodismo, vive bajo acoso, y con ello se amedrenta a una parte significativa de quienes ejercen cotidianamente la libertad de expresión. México se consolida como uno de los países más peligrosos para ejercer el periodismo, de por sí amordazado por los poderes fácticos: entre 2001 y 2012 al menos 109 periodistas fueron asesinatos o desaparecidos. ${ }^{20}$

\section{CONCLUSIÓN}

La estrategia de acumulación en México recurre a estrategias violentas basadas en la corrupción, la transferencia de excedente, la represión salarial, la dependencia alimentaria, el extractivismo y la militarización. La diferenciación social ha propiciado la concentración de capital y riqueza en un pequeño núcleo de la élite a cambio de la proliferación de la pobreza, la precarización, el hambre y la muerte.

La disyuntiva epocal es de gran calado: o el capital o la vida. Optar por privilegiar los intereses corporativos significa profundizar el despojo, la explotación, la dominación y la discriminación, con el agregado del realismo salvaje que atenta directamente contra la vida por medios coercitivos y punitivos para garantizar el control político de la población y las exigencias corporativas. Optar por la vida, por la reproducción de la vida humana en condiciones dignas, amerita cambiar los principios del modelo de desarrollo, de modo que se guíe por preceptos como la soberanía laboral y alimentaria, el trabajo digno y remunerativo, la democracia formal, participativa y social.

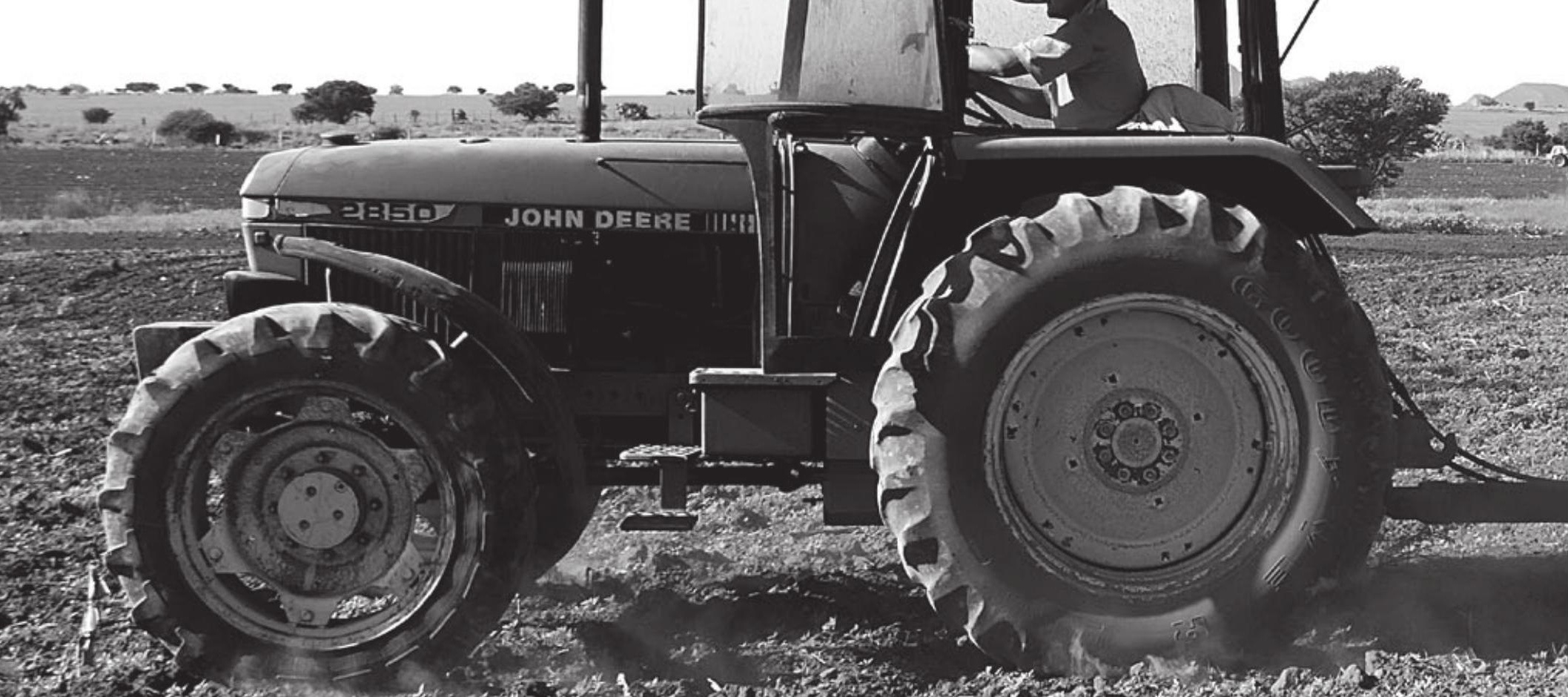


1 Según el reporte de la OCDE, Divididos resistimos: ¿por qué sigue aumentando la desigualdad? Entre miembros de la OCDE, en promedio el ingreso de la décima parte de la población más rica fue casi nueve veces el ingreso del 10\% más pobre. Ixel Yutzil González, «Crece en México la desigualdad social: OCDE», El Universal, 6 de diciembre de 2011, en 〈http://www.eluniversal.com.mx/notas/814028.html .

2 Fernando Franco, «Sólo en México, 52 millones de pobres vs. 11 millonarios», El Economista, 8 de marzo de 2012, en «ttp://eleconomista.com. $\mathrm{mx} /$ inventario/2012/03/08/solo-mexico-52millones-pobres-vs-11-millonarios .

3 (s.a.) «México/ empresas: "alta" corrupción», BвCMundo.com, 27 de mayo de 2002, en 〈http://news.bbc.co.uk/hi/spanish/business/ newsid_2010000/2010939.stm>.

4 Roberto González, «Contraproducente, limitar a bancos el pago de dividendos», La Jornada, 15 de mayo de 2012, en «http://www.jornada.unam. mx/2012/05/15/economia/023n1ecor.

5 Dolores Acosta, «Recapitalizan a matrices los bancos en México: A.regional», El Sol de México, 17 de septiembre de 2012, en 〈http:// www.oem.com.mx/lavozdelafrontera/notas/ n2697566.htm〉.

6 Isabel Mayoral, «Lavado de dinero en HSBC, desde Bital», CNNExpansión, 18 de julio de 2012, en http://www.cnnexpansion.com/economia/ 2012/07/17/lavado-de-dinero-en-hsbc-desde-bital>.

7 (s.a.), «Revelan en EU posible lavado de dinero en Walmart México», Proceso, 14 de agosto de 2012, en 〈http://www.proceso.com.mx/?p=317041〉.
8 Según el Centro de Análisis Multidisciplinario (CAM) de la UNAM.

9 Roberto González, «Desplazan mercancías mexicanas a las de China en EU a costa de salarios», La Jornada, 29 de septiembre de 2012, en 〈http://www. jornada.unam.mx/ultimas/2012/09/23/94913611-desplazan-mercanciasmexicanas-a-las-de-china-en-estados-unidos-a-costa-de-salarios/>.

10 Georgina Olson, «Hambre mata más que narco; hay 12 millones sin canasta básica», Excélsior, 19 de febrero de 2012, en 〈http://www.excelsior.com.mx/ index.php? $\mathrm{m}=$ nota\&id_nota $=811635$ >

11 (s.a.), «México: pobreza y hambre como nunca antes», Sin embargo.mx, 18 de octubre de 2012, en 〈http://www.sinembargo.mx/opinion/18-09-2012/9590).

12 Fabiola Martínez, «Padecen despoblamiento casi 70\% de los municipios rurales del país: Conapo», La Jornada, 2 de diciembre de 2010, en (Conapo, La situación demográfica de México 2010), 〈http://www.jornada.unam. $\mathrm{mx} / 2010 / 12 / 02 /$ politica/016n1pol〉.

13 wwF México (World Wide Fund for Nature).

14 〈http://www.sinembargo.mx/29-02-2012/165749».

15 Isaac Torres, «En 30 años, México ha perdido 50 especies; 40\% sigue en riesgo», La Crónica de hoy, 22 de abril de 2007, en 〈http://www.cronica.com. $\mathrm{mx} /$ nota.php?id_nota $=297057$.

16 Nancy Flores, «320 mil millones para seguridad nacional», Contralínea, 22 de abril de 2012, en 〈http://contralinea.info/archivo-revista/index. php/2012/04/22/320-mil-millones-para-seguridad-nacional/>.

17 Ana Lilia Pérez, «Tráfico de armas, el negocio de la muerte», Contralínea, 16 de noviembre de 2011, en 〈http://contralinea.info/archivo-revista/index. php/2011/11/16/trafico-de-armas-el-negocio-de-la-muerte/s.

18 Emir Olivares, «Unidos, Movimiento por la Paz y \#YoSoy132 exigen detener la "guerra inútil" antinarco», La Jornada, 21 de septiembre de 2012, en 〈http://www.jornada.unam.mx/2012/09/21/politica/018n1pol〉.

19 Flor Goche, «México: cinco feminicidios al día», Contralínea, 15 de marzo de 2012, en 〈http://contralinea.info/archivo-revista/index.php/2012/03/15/ mexico-cinco-feminicidios-al-dia/>.

20 Mariela Paredes, «Panismo: 109 periodistas asesinados o desaparecidos», Contralínea, 3 de mayo de 2012, en «http://contralinea.info/archivo-revista/index. php/2012/05/03/panismo-107-periodistas-asesinados-desaparecidos/>.

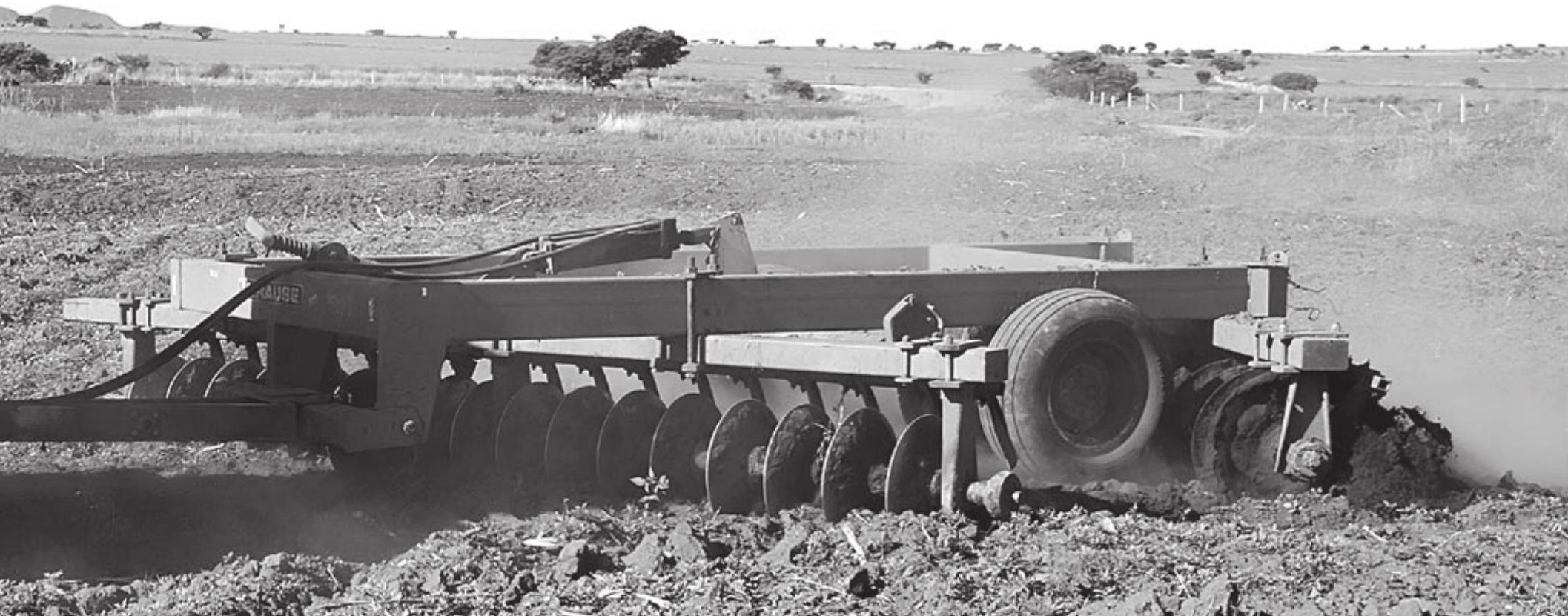

